\title{
Continuing bonds in adjustment to bereavement: Impact of abrupt versus gradual separation
}

\author{
MARGARET S. STROEBE ${ }^{a}$ GEORGIOS ABAKOUMKIN, ${ }^{b}$ \\ WOLFGANG STROEBE, ${ }^{a}$ AND HENK SCHUT ${ }^{a}$ \\ ${ }^{a}$ Utrecht University, The Netherlands and ${ }^{b}$ University of Thessaly, Greece
}

\begin{abstract}
There is debate whether continuing bonds with a deceased person help or hinder adaptation to bereavement. This longitudinal study examined causal relationships between continuing bonds and symptoms over time. Following attachment theory predictions, suddenness of separation was examined as a moderator. Data were obtained from 60 bereaved spouses at 3 points across the first 2 years of bereavement. Measures included expectedness of death, grief and depression measures, and a continuing bonds index. Persons with unexpected loss who retained strong bonds were the least well adapted and remained so over time. Those with expected loss and strong ties suffered initially but improved. Those with weaker ties had lower scores on maladaptation, regardless of (un)expectedness of death. Theoretical and applied implications are discussed.
\end{abstract}

In the 1980s, the scientific study of attachment patterns in human relationships was extended from infant-caregiver (Bowlby, 1953) to the formation and maintenance of adult romantic relationships (Hazan \& Shaver, 1987). Around this time, it was also postulated that there could be continuity between these attachments and reactions following the ending of a relationship through the death of a loved person (Bowlby, 1980). In line with a basic premise of attachment theory (Scharfe \& Bartholomew, 1994), it was understood that the type of attachment manifested during childhood and carried through to adulthood (Fraley \& Davis, 2005) could also profoundly influence the nature of the grief (separation)

Margaret S. Stroebe, Department of Clinical and Health Psychology, Utrecht University, Utrecht, The Netherlands; Georgios Abakoumkin, Department of Preschool Education, University of Thessaly, Volos, Greece; Wolfgang Stroebe and Henk Schut, Department of Clinical and Health Psychology, Utrecht University, Utrecht, The Netherlands.

Correspondence should be addressed to Margaret S. Stroebe, Department of Clinical and Health Psychology, Utrecht University, P.O. Box 80.140, 3508 TC Utrecht, The Netherlands, e-mail: m.s.stroebe@uu.nl. reaction during bereavement (Parkes, 2006). Following the latter line of investigation, bereavement researchers used the concept of continuing bonds, to explore how ongoing attachment functions during bereavement. Continuing bonds has been defined as the presence of an ongoing inner relationship with the deceased person (Shuchter \& Zisook, 1993). According to both scientific and lay accounts, throughout most of the 20th century it was understood that continuing bonds was unhealthy, that ties to a deceased person needed to be relinquished in order to get over the loss of a loved person (for a review, see Stroebe, Gergen, Gergen, \& Stroebe, 1992). According to early psychoanalytic formulations, from which subsequent theoretical and therapeutic principles were derived (e.g., Rando, 1984; Raphael, 1983; Sanders, 1989; Worden, 1982/2008), the energy invested in the deceased loved one (i.e., attachment to the person) needed to be "worked through" to enable it to be withdrawn and invested in another person (Freud, 1917/1957). Complications in grief were associated with the inability to relinquish ties to the deceased. 
This dominant view was challenged in the 1990s (e.g., Klass, Silverman, \& Nickman, 1996; Stroebe et al., 1992). For example, Klass and colleagues (1996) examined the ways in which the bereaved continue their bonds with the deceased persons, arguing that there were benefits for the bereaved in retaining connections with their deceased and drawing the general conclusion that, in contrast to previous claims, continuing bonds with the deceased during bereavement is adaptive. Stroebe and colleagues (1992) drew examples from historical and cultural perspectives to illustrate the functions that continuing bonds could serve for bereaved people, including the giving of meaning to ongoing life (e.g., through providing meaningful connection with the past) or retaining of one's identity and sense of self (e.g., by following the wishes of the deceased person; using him or her as an ongoing example).

Recent research has failed to provide unequivocal support either for the position that relinquishing ties or that continuing bonds is necessary for adaptation, although, on balance, there seems more evidence that continuing bonds are associated with poor rather than good adjustment (an assumption that we therefore make in this investigation; see Field, 2008; Stroebe \& Schut, 2005 reviews). For example, despite the claims made by Klass and colleagues (1996), Field, Gal Oz, and Bonanno (2003) found that continuing bonds was associated with worse adjustment over a 5-year postbereavement period. However, in a study of early-bereaved (4 months postloss) and later-bereaved (2 years postloss) individuals, Field and Friedrichs (2004) reported both negative and positive relationships between continuing bonds and adjustment among the later-bereaved sample.

Clearly, then, the relationship between relinquishing or continuing bonds and adjustment to bereavement is more complex than was claimed in the assumptions of either of the original blanket formulations. Recognizing this, researchers have recently begun to explore possible components or determinants of the impact of bonds on adaptation, albeit more on a theoretical than empirical level. First, the role of individual differences in effective versus ineffective use of continuing bonds in coping with bereavement has received some theoretical attention (e.g., Field, Gao, \& Paderna, 2005). For example, there are good reasons to argue for differences in the efficacy of relinquishing versus continuing bonds in relationship to the bereaved individual's attachment style, with insecure attachment relating to "unhealthier" continuing bonds and poorer adaptation than for those with secure attachment styles (Stroebe, Schut, \& Boerner, 2010).

Second, researchers have focused on types of continuing bonds in relationship to adjustment, identifying different dimensions such as searching for the deceased or sensing the deceased's presence (for a review, see Field, 2008). Field, Nichols, Holen, and Horowitz (1999), using the same database as the subsequent study by Field and colleagues (2003), reported that earlier after the death, the relationship of continuing bonds with adjustment was dependent on the type of retained bond. Bereaved individuals who reported obtaining greater comfort through memories of the deceased expressed less helplessness, whereas those who at 6 months postloss maintained the deceased's possessions just as they were when alive, had more severe grief symptoms over the course of 25 months. In one of few studies using a longitudinal design, and building on the previous investigation by Field and colleagues, Boelen, Stroebe, Schut, and Zijerveld (2006) found a differential influence of different types of manifestations of continuing bonds on various kinds of responses to loss. For example, continuing bonds through recalling memories was a strong predictor of grief but not depression, whereas continuing bonds through using the deceased's possessions was a weak predictor of both these types of responses (patterns that were somewhat different from those found by Field et al., 1999). The reasons for the discrepancies between these studies are as yet unclear.

The attachment theory perspective (for a recent review, see Cassidy \& Shaver, 2008) suggests an additional factor that is likely to be important in determining the impact of bonds on outcome, namely, the nature of the separation itself. To our knowledge, this 
aspect has so far received no specific theoretical or empirical attention in the investigation of continuing bonds. As attachment theory focuses on separation phenomena, it would follow from this perspective that the precise nature of the relinquishment of the bond would be critical for bereavement outcome. Examination of the type of death itselfthat is, the circumstances of the death event-provides a useful starting point for the investigation of this factor. In line with this, Bowlby (1980) himself drew attention to the circumstances of loss (notably, sudden, unexpected death) as one of the conditions affecting the course of grief: type of separation thus featured in his theoretical analysis. Some studies have indeed provided evidence that sudden deaths are associated with poorer bereavement outcome than expected ones (e.g., Caserta, Lund, Utz, \& de Vries, 2009), although results are not completely unequivocal (e.g., Carr, House, Wortman, Nesse, \& Kessler, 2001). Sudden deaths are likely to have more impact on vulnerable people (e.g., those with low self-esteem) and those who are personally less well prepared (e.g., Ong, Bergeman, \& Bisconti, 2005). Unexpected death of a close person is an event that can, for example, trigger psychiatric morbidity (Barry, Kasl, \& Prigerson, 2002). Such health impacts are likely to be mediated by the quality of the relationship with the sick person (Feeney \& Hohaus, 2005) and associated attachment-related emotions (Mikulincer \& Shaver, 2010).

There are two main ways in which the expectedness of a loss, continuing bonds, and poor adjustment could be associated. On the one hand, as suggested by attachment theory and following the line of reasoning outlined above, it is possible that the efficacy of continuing bonds as a coping strategy would depend on (i.e., be moderated by) the extent to which the loss was expected. In this case, it would seem most plausible that unwillingness to relinquish bonds to the deceased would be particularly detrimental to adjustment following a death that came unexpectedly, because there would be no opportunity to prepare for living without the physical presence of the loved person. Persons who are closely bonded and who suffer the sudden loss of their loved one would be expected to have more difficulty adjusting to their bereavement than those who were not so closely bonded and whose loved one did not die suddenly (Hypothesis 1).

Alternatively, continuing bonds might be a general coping strategy that bereaved individuals use in coping with the death of a loved one, regardless of whether the loss was unexpected or expected. In this case, there would be no association between expectedness of loss and continuing bonds. A negative impact of continuing bonds on adjustment would be unaffected (i.e., not moderated) by the degree to which a loss was expected (Hypothesis 2).

Thus, the main purpose of this study was to try to establish the role of expectedness of loss in the associations of continuing bonds with adjustment, and to shed light on the alternative possibilities suggested above. The design of this study incorporated certain advantages over previous ones. By using a longitudinal design, our study remedied a major limitation of many earlier studies of the relationship between continuing bonds and adaptation that used cross-sectional designs (e.g., Field \& Friedrichs, 2004; Field et al., 2003). This study enabled examination of the relationship between continuing bonds and adaptation over a 2-year postbereavement period.

Our study was also designed to address a further problem of earlier research, namely, the conceptual overlap between measures of grief and continuing bonds (see Schut, Stroebe, Boelen, \& Zijerveld, 2006), which complicates the examination of associations between these concepts. Since unwillingness to relinquish bonds can be considered part of the grief syndrome, grief scales often contain items that assess continuing bonds. To illustrate, items on the Texas Revised Inventory of Grief (TRIG; Faschingbauer, 1981) and the Continuing Bonds Scale (CBS; Field et al., 1999) are quite similar: "I am preoccupied with thoughts (often think) about the person who died" is a TRIG item, whereas "I seek out things to remind me of my spouse" is a CBS item. With such conceptual overlap, a high correlation between a measure of grief and of continuing bonds may tell us little about the role of continuing bonds in adjusting to loss. 
In this study, we took two steps to avoid the problem of conceptual overlap: (a) we made sure that our measure of grief did not contain items that assessed continuing bonds and (b) we included a measure of depression as a general (nongrief) indicator of adjustment. Including both depression and grief as dependent measures is important for another reason: Symptoms of grieving form a separate cluster from those associated with depression (Prigerson, 1995) and relate to different predictors (see Wijngaards-de Meij et al., 2005). Including depression and grief enables relationships to be explored across the broader range of both grief-specific and non-griefspecific measures on the one hand, and the other investigated variables on the other.

The current investigation is both theoretically and clinically relevant. It is important to establish whether (and/or in what manner) continuing bonds are related to bereavement adjustment and to examine for whom continuing bonds may be (mal)adaptive. At present, it is still unclear whether (some) bereaved persons should be encouraged to relinquish their ties with the deceased, to avoid complications in grieving, or whether (or for whom) it is healthier to continue ties. Yet, it is critical for the design of intervention for those suffering complications in their grieving: Should mental health care professionals focus on assisting clients in loosening ties to the deceased, or precisely the opposite, should close retained bonds be supported and encouraged?

\section{Method}

\section{Participants}

Widowed persons' data were obtained as part of the Tübingen Longitudinal Study of Bereavement, an in-depth study of risk factors in adjustment to conjugal bereavement (Stroebe \& Stroebe, 1993). Widowed individuals (30 widows and 30 widowers) living in Southern Germany participated in the study. The mean age of this group was 53 years $(S D=6.81)$. Names, addresses, and sociodemographic information were supplied by the local registrars' offices. Information was available for all persons in this age category listed in these offices whose spouses had died from 4 to 6 months previously. Sixty individuals participated at Time 1, 55 at Time 2, and 49 at Time 3. Thus, 82\% participated in all three interviews; there was no significant health difference between those who participated in three sessions and those who dropped out.

\section{Procedure}

All persons in this category were first sent a letter asking for their cooperation in the study, followed by a telephone call some days later. No pressure was put on persons to participate. Although the general level of acceptance was rather low (28\% at Time $1 ; 217$ were approached), this rate was not atypical for bereavement research (Stroebe \& Stroebe, 1989). Furthermore, the sociodemographic characteristics of the widows and widowers were similar to each other and not substantially different from those who had refused to participate (Stroebe \& Stroebe, 1989).

The participants were interviewed three times: (a) 4-7 months after their loss, in their homes; (b) approximately 14 months after loss, also at home; and (c) just over 2 years after the loss, by telephone. Data collection involved questionnaires containing self-report scales (including the depression, grief, and continuing bonds scales used here) as well as the semistructured interviews.

\section{Measures}

\section{Expectedness of loss}

The bereaved were asked whether they had forewarning of the partner's death and, if so, how long (in weeks). Forewarning ranged from 0 to 420 weeks $(M=32.68$ weeks, $S D=68.45)$. For conducting analyses of variance (ANOVAs), this variable was dichotomized into two categories by median split. A loss was categorized as unexpected if the bereaved had no $(n=27)$ or 1 week $(n=4)$ potential preparation time for impending loss Except for two suicides and three cases of "resulting from an operation," all the unexpected losses were due to natural causes (mostly heart disease); most expected losses were due to cancer. 
Table 1. Factor loadings for the continuing bonds items

\begin{tabular}{|c|c|c|}
\hline \multirow[b]{2}{*}{ Subscale and item } & \multicolumn{2}{|c|}{ Factor loading } \\
\hline & $\mathrm{F} 1$ & $\mathrm{~F} 2$ \\
\hline \multicolumn{3}{|l|}{ Non-Relinquishment } \\
\hline (a) I think I have now accepted that he has left me for ever (R) & & .85 \\
\hline $\begin{array}{l}\text { (b) I have now got used to the fact that he will never come } \\
\text { through the door }(\mathrm{R})\end{array}$ & & .91 \\
\hline $\begin{array}{l}\text { (c) I know that it doesn't make sense, but I sometimes find } \\
\text { myself looking for her }\end{array}$ & & .63 \\
\hline \multicolumn{3}{|l|}{ Connectedness } \\
\hline (d) I like to do things exactly as he did & .48 & \\
\hline (e) I have left all his things just as they were & .95 & \\
\hline (f) I have given away his clothes (R) & .93 & \\
\hline
\end{tabular}

Note. Only factor loadings with an absolute value greater than .30 are reported. "( $\mathrm{R})$ " indicates that the respective item was reverse-coded for the analyses.

\section{Continuing bonds}

This variable was measured with six items ( $\alpha=.65$; Table 1$)$. In line with Field and colleagues' (1999) and Boelen and colleagues' (2006) expansion of continuing bonds beyond the phenomenon of "sense of the presence of the deceased," these items were intended to reflect two core components of continuing bonds: unwillingness to relinquish the bonds and connectedness with the deceased. NonRelinquishment of bonds $(\alpha=.72)$ included items (a) to (c) and Connectedness $(\alpha=.75)$ comprised items (d) to (f). These items had a true-false response format.

To examine whether we succeeded in distinguishing between two components within the continuing bonds measure, we conducted a principal components factor analysis with varimax rotation on these six items. Two factors with eigenvalues greater than 1 were extracted. These factors explained $66.95 \%$ of the variance. The items loaded on the two factors as intended (Table 1): items (d) to (f) loaded on the first factor (Continuing $B$ onds: $C$ onnectedness [CB-C]; eigenvalue 2.18 , accounting for $36.30 \%$ of the variance) and items (a) to (c) loaded on the second factor (Continuing Bonds: Non-Relinquishment [CB-NR]; eigenvalue 1.84, accounting for $30.65 \%$ of the variance). In addition, $\mathrm{CB}-\mathrm{C}$ and $\mathrm{CB}-\mathrm{NR}$ were not correlated, $r(60)=.11, n s$.

\section{Grief}

Grief was measured with 13 items from a scale constructed for use in Germany, the so-called Tübingen Bereavement Symptoms Questionnaire (TBSQ), forming the Tübingen Grief Scale (TGS). Selection of items for the TGS from the larger battery was guided by the work of Prigerson and colleagues (2009). The items selected were similar to those on their Inventory of Complicated Grief (ICG) and somewhat paralleled their proposed criteria for Prolonged Grief Disorder (PGD) formulated for the Diagnostic and Statistical Manual of Mental Disorders, 5th edition (DSM-5; Prigerson et al., 2009). TGS items differed in style/formulation from the ICG. Furthermore, the aim here was to inventorize grief symptoms, while that of Prigerson and colleagues (2009) was to tap symptoms of prolonged grief disorder. Examples of items of the TGS are "Sometimes I long for him so much that I can't think of anything else" and "I can't really get interested in anything any more." The items had a true-false response format. The TGS had a satisfactory internal consistency (Time 1: $\alpha=.80$; Time 2: $\alpha=.83$; Time 3: $\alpha=.82$ ). Although the TGS (at Time 1) was correlated with the continuing bonds measure, $r(60)=.55, p<.001$, this overlap was evident only for the NonRelinquishment subscale, $r(60)=.63, p<$ 
.001 , but not for the Connectedness subscale, $r(60)=.16, n s$.

\section{Depression}

Even though we addressed the possibility of conceptual overlap between measures of continuing bonds and grief by excluding items from the grief scale that related to continuing bonds, we nevertheless felt it was important to have an independent, generic measure of psychological adjustment. The German version of the Beck Depression Inventory (BDI; Kammer, 1983) was therefore included. The BDI consists of 21 items that assess major symptoms of depression. The item "lack of sexual interest" was not used because pretest data had shown that the bereaved persons in our sample were sometimes upset about having to respond to this question. The BDI had satisfactory internal consistency at all three time points (Time 1: $\alpha=.86$; Time 2: $\alpha=.89$; Time 3: $\alpha=.88$ ). Like the TGS, the BDI (at Time 1) correlated significantly with CB-NR, $r(59)=.44, p<.001$, but not with $\mathrm{CB}-\mathrm{C}, r(59)=.22 ; n s$.

\section{Results}

To test our hypotheses, we examined the joint role of continuing bonds and expectedness of loss on adjustment to loss over time. ${ }^{1}$ To recap, one possibility is that continuing bonds as a coping strategy would be moderated by loss expectedness (Hypothesis 1); that is, interactions between continuing bonds and loss expectedness on adjustment measures would be expected. However, continuing bonds might be a general

1. Continuing bonds (CB) was used as a predictor at Time 1 (only). It is to be noted that $\mathrm{CB}$ declines over time and that it is not related to expectedness. At Time 1 , connectedness does not differ between participants experiencing an unexpected loss $(M=2.03, S D=$ $1.17)$ and participants for whom the loss was expected $(M=2.28, S D=0.96), t(58)<1$. Similarly, there was no difference with regard to non-relinquishment (unexpected: $M=1.26, S D=1.12$; expected: $M=$ $1.24, S D=1.24), t(58)<1$. Furthermore, $\mathrm{CB}$ at Time 1 is moderately to strongly correlated with $\mathrm{CB}$ at later time points - connectedness correlations: $\mathrm{T} 1$ with $\mathrm{T} 2 r(55)=.50$, T1 with $\mathrm{T} 3 r(49)=.40$; nonrelinquishment: $\mathrm{T} 1$ with $\mathrm{T} 2 r(55)=.65$, $\mathrm{T} 1$ with $\mathrm{T} 3$ $r(49)=.60$. coping strategy unaffected by expectedness of loss (Hypothesis 2); that is, only main effects of continuing bonds on adjustment measures would be expected without interactions between continuing bonds and loss expectedness. Thus, the BDI and TGS scores were submitted to 2 (continuing bonds: low vs. high) $\times 2$ (expectedness of loss: unexpected vs. expected) $\times 3$ (time: Time 1 vs. Time 2 vs. Time 3) ANOVAs with repeated measures on the last factor. Separate analyses were conducted for each of the two continuing bonds measures. Assignment of participants to levels of continuing bonds and expectedness of loss was performed according to median splits on the respective measures assessed at Time 1.

\section{Non-Relinquishment of bonds}

The Non-Relinquishment $\times$ Expectedness of Loss $\times$ Time ANOVA on the BDI yielded main effects of non-relinquishment, $F(1,44)$ $=15.35, p<.001, \eta^{2}=.26$; expectedness of loss, $F(1,44)=12.27, p<.01, \eta^{2}=.22$; and time, $F(2,88)=15.13, p<.001, \eta^{2}=$ .26 (partial eta-squared values are reported throughout the text). Bereaved who did not relinquish their bond with the deceased and for whom the loss was unexpected were more depressed than were those who relinquished their bonds and for whom the death of the spouse was expected (Figure 1). Finally, depressive symptoms decreased over time. However, these main effects were moderated by two 2-way interactions, a NonRelinquishment $\times$ Expectedness of Loss interaction, $F(1,44)=9.66, p<.01, \eta^{2}=.18$, and a Non-Relinquishment $\times$ Time interaction, $F(2,88)=4.80, p<.05, \eta^{2}=.10$, which were further qualified by a threeway interaction, $F(2,88)=8.18, p<.01$, $\eta^{2}=.16$. As inspection of Figure 1 and simple main effect analysis indicate, expectedness of loss was associated with higher depression scores mainly for individuals who were unwilling to relinquish their bond with the deceased. Individuals experiencing an unexpected loss displayed increased depression scores that did not substantially decline over time (Time 1: $M=19.43, S D=11.63$; 


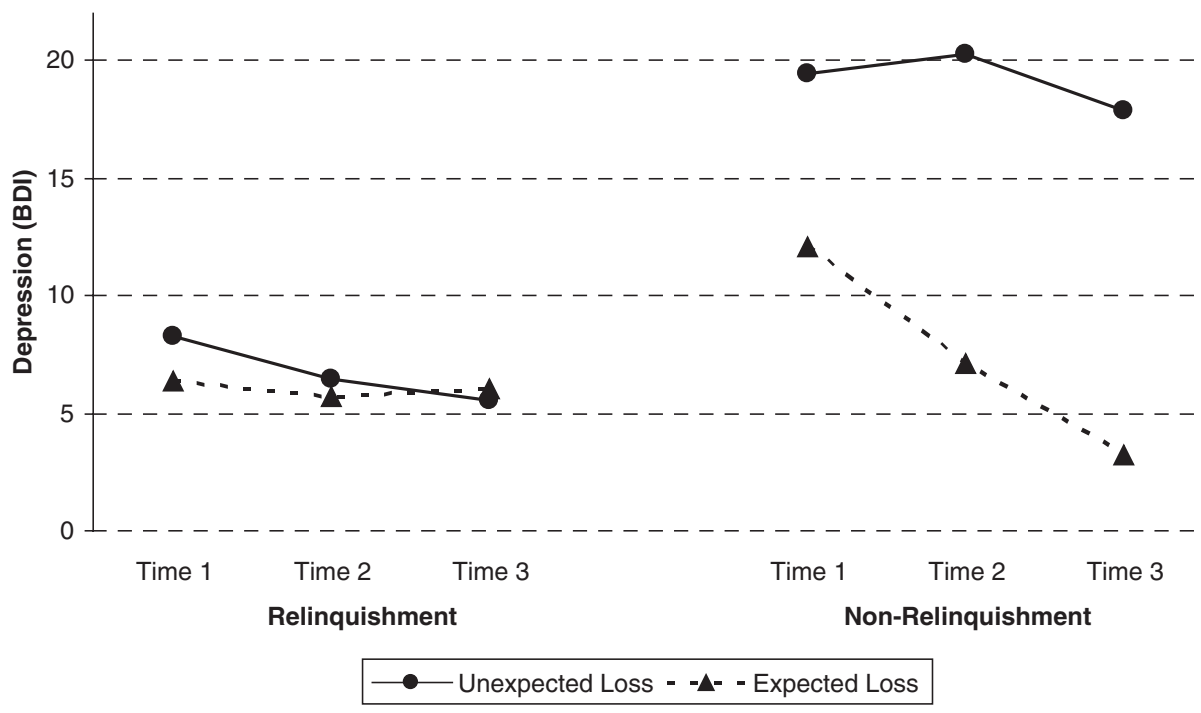

Figure 1. Depression scores (Beck Depression Inventory [BDI]) by non-relinquishment, expectedness of loss, and time.

Time 2: $M=20.29, S D=9.96$; Time 3: $M=$ $17.86, S D=9.23)$. In contrast, those who had been able to anticipate their loss improved over time (Time 1: $M=12.11, S D=3.95$; Time 2: $M=7.11, S D=3.62$; Time 3: $M=$ $3.22, S D=3.19)$. In addition, bereaved persons experiencing an unexpected loss, but willing to relinquish their bonds, showed an improvement from Time $1 \quad(M=8.29$, $S D=5.32)$ to Time $3(M=5.53, S D=$ 5.67), whereas their Time 2 scores $(M=$ $6.41, S D=6.71$ ) did not differ significantly from the scores in Time 1 and Time 3. This interaction rules out Hypothesis 2 with regard to one of the measures of continuing bonds but is consistent with Hypothesis 1 .

The Non-Relinquishment $\times$ Expectedness of Loss $\times$ Time ANOVA on the TGS yielded a pattern of results that was similar to the one observed on the BDI scores. There were the same main effects of non-relinquishment, $F(1,45)=10.68, p<.01, \eta^{2}=.19$; expectedness of loss, $F(1,45)=5.67, p<.05$, $\eta^{2}=.11 ;$ and time, $F(2,90)=18.46, p<$ $.001, \eta^{2}=.29$. These effects were moderated by a Non-Relinquishment $\times$ Time interaction, $F(2,90)=5.56, p<.01, \eta^{2}=.11$, which was further qualified by a three-way interaction of Non-Relinquishment $\times$ Expectedness of Loss $\times$ Time, $F(2,90)=9.11$, $p<.001, \eta^{2}=.17$ (Figure 2). The pattern of this interaction is similar to the pattern of the interaction on the BDI scores (Figure 1) and thus also inconsistent with Hypothesis 2.

According to simple main effects analysis, bereaved individuals who were unwilling to relinquish their bonds exhibited a marked decrease in grief over time after an expected loss (Time 1: $M=6.78, S D=2.82$; Time 2: $M=3.67, S D=2.35$; Time $3: M=2.22$, $S D=1.99)$ but not after a loss that was sudden (Time 1: $M=7.71, S D=3.30$; Time $2: M=7.57, S D=3.78$; Time $3: M=6.57$, $S D=2.76$ ). At a much lower level of grief, bereaved individuals who were willing to relinquish their bonds showed a decrease in grief over time after an unexpected (Time $1: M=4.44, S D=3.18$; Time $2: M=3.17$, $S D=3.22$; Time 3: $M=2.94, S D=3.30$ ), but not an expected loss (Time 1: $M=2.87$, $S D=2.07$; Time $2: M=2.80, S D=2.04$; Time 3: $M=2.73, S D=2.60$ ).

\section{Connectedness}

The Connectedness $\times$ Expectedness of Loss $\times$ Time ANOVA on the BDI yielded a main effect of time, $F(2,88)=8.67, p<.001$, $\eta^{2}=.17$, showing an overall improvement 


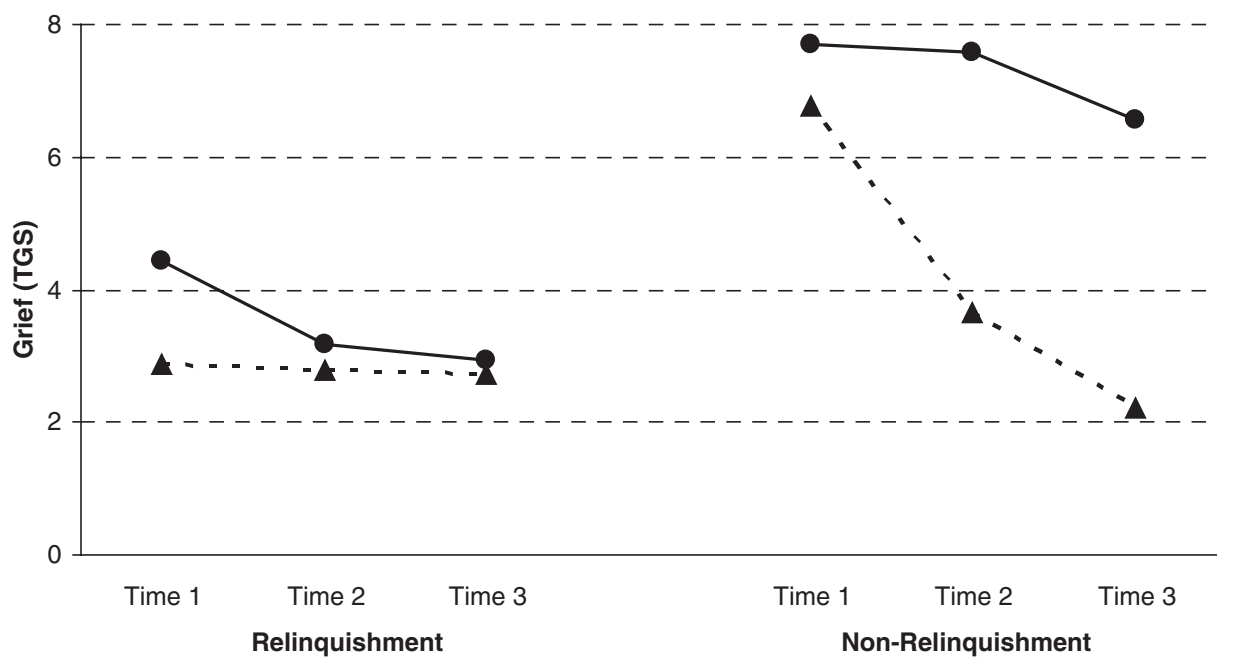

$\longrightarrow$ Unexpected Loss - -A- - Expected Loss

Figure 2. Grief scores (Tübingen Grief Scale [TGS]) by non-relinquishment, expectedness of loss, and time.

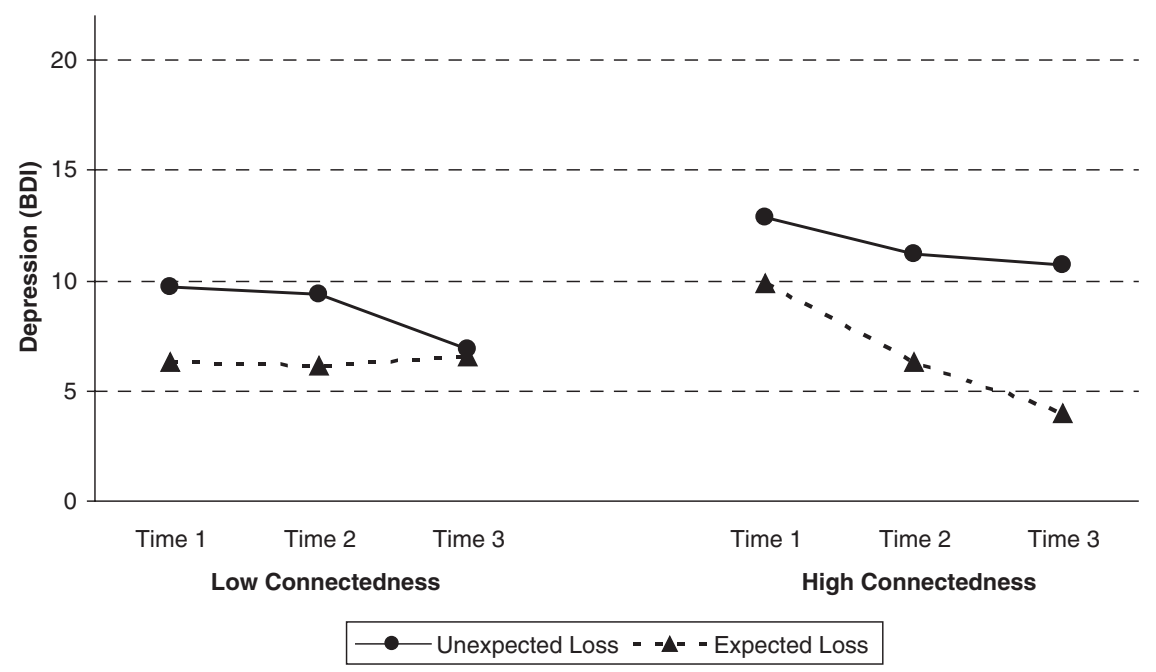

Figure 3. Depression scores (Beck Depression Inventory [BDI]) by connectedness, expectedness of loss, and time.

in depression over time. This main effect was moderated by a three-way interaction, $F(2,88)=3.72, p<.05, \eta^{2}=.08$. Simple main effects analysis indicated that the time main effect was only evident within one participant subgroup, namely those participants who maintained high connectedness and for whom the loss of their partner was expected (Figure 3). These participants exhibited a decline in BDI scores from Time 1
$(M=9.87, S D=5.94)$ to Time $2(M=$ $6.33, S D=4.95)$ to Time $3 \quad(M=4.00$, $S D=4.28)$. A contrasting pattern occurred for participants who also maintained high connectedness but for whom their partner's loss came unexpectedly: These individuals had relatively high BDI scores that did not decline over time. Again, this pattern is inconsistent with Hypothesis 2 but supportive of Hypothesis 1. 


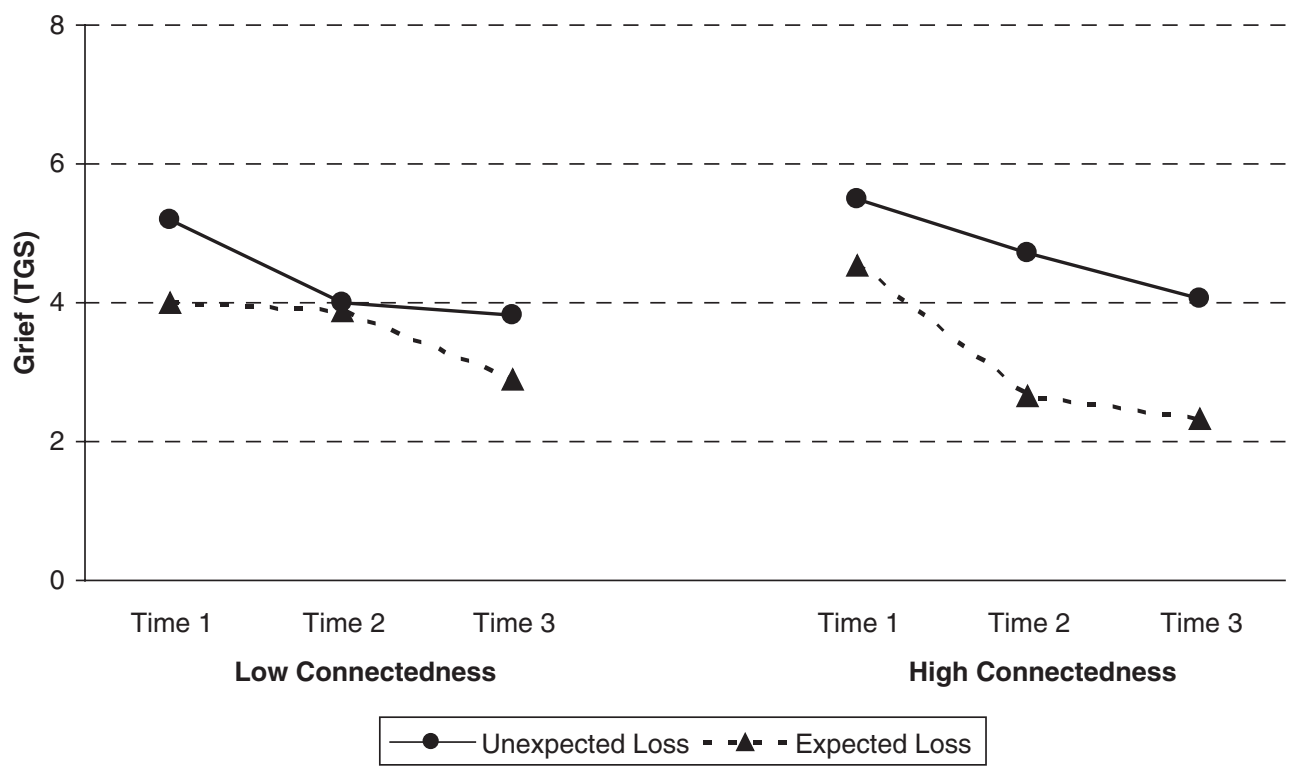

Figure 4. Grief scores (Tübingen Grief Scale [TGS]) by connectedness, expectedness of loss, and time.

The Connectedness $\times$ Expectedness of Loss $\times$ Time ANOVA on TGS yielded only a main effect of time, $F(2,90)=11.05, p<.001$, $\eta^{2}=.20$, which was not qualified by any of the other variables (Figure 4). This effect reflected an overall decrease in grief over time. Participants exhibited more grief at Time $1(M=4.86, S D=3.27)$ than at Time 2 $(M=3.78, S D=3.18)$, which was still more than at Time $3(M=3.26, S D=3.06)$.

\section{Discussion}

In this study, we examined the relationship between continuing bonds and adjustment to bereavement, a topic that extends scientific interest in personal relationships across the life span to include the nature of continuing attachment to a deceased loved person. In particular, it is a topic of ongoing concern among bereavement researchers and of interest to caregivers, given the existence of discrepant views about the efficacy of continuing versus relinquishing ties with the deceased and their implications for professional intervention. Finer-grained investigation has been called for to illuminate this relationship. Our contribution focused on one aspect in particular, namely, the nature, in terms of expectedness, of the separation from the deceased person. We also examined the type of bond in relationship to adaptation.

Some noteworthy general patterns emerged from our analyses. First, although we noted an inconsistency in the literature regarding the impact of expectedness, among our younger bereaved sample unexpectedness of loss was associated with both higher grief and depression: Having time to adjust to the loss of a younger partner does to some extent appear to ease the pain of loss. Furthermore, bereaved people who did not relinquish their bond with the deceased 4-7 months postloss were both more grief stricken and more depressed than those who relinquished their bonds. In addition, persons who lost their loved one unexpectedly were similarly closely tied to their deceased as those who expected the loss to happen. This speaks against the possibility that a negative association between continuing bonds and adjustment to loss could be a by-product of an association of continuing bonds with expectedness of loss rather than a causal effect of continuing bonds as a coping strategy. Finally, both grief and depressive 
symptoms decreased over time, indicating a gradual adjustment to the loss.

Turning next to the hypotheses: We found support for Hypothesis 1 rather than Hypothesis 2. Persons with strong ties to the deceased person whose loss was unexpected had the most difficulty in adjusting to their bereavement; the relationship between bonds and adjustment was indeed moderated by the type of separation from the deceased, with more difficulties associated with unexpected losses and close ties, as we elaborate below. Contrary to the claim of Klass and colleagues (1996) that continuing bonds facilitate coping with bereavement, we found no support for our alternative hypothesis that continuing bonds is a generally adaptive coping strategy that bereaved individuals use to cope with the loss of their loved one. Klass and colleagues based their claims on theoretical propositions and some qualitative or case study illustrations; no quantitative empirical analysis was included linking continuing bonds to good adjustment. Our study contributes to the growing body of evidence showing that the general claim that continuing bonds is adaptive is not valid, for certain subgroups it may even be maladaptive.

Despite a few differences in patterns for the two types of bonds (non-relinquishment being related to symptoms, connectedness not) and for the dependent variables of depression versus grief (lack of significance in the pattern for connectedness on the grief variable), it seems that we have identified an important subgroup of bereaved persons who may be at risk of poor outcome to bereavement over time. Quite consistently, the results show that those persons who have experienced an unexpected bereavement, and who retain close bonds to the deceased person, fail to recover over time. By contrast, those who likewise have strong bonds to the deceased, but who have had time to adjust to an impending loss (and possibly prepare for and talk things through with their sick spouse before death) manage over time to adjust well. Persons who do not have such strong ties, irrespective of whether death was expected or unexpected, adjust well to their loss.
These results are in line with attachment theory. The sudden wrenching away from a loved one to whom one (retrospectively at least) feels very closely bonded is much harder to come to terms with than one where there is time for preparation and prebereavement adjustment. Of course, the nature of the separation is not the only important determinant (also, our measure of separation was restricted to a simple measure of un/expectedness). Future research could extend investigation to include other factors such as the style of attachment (and other individual difference variables such as neuroticism), and process variables (i.e., coping strategies such as disclosure of emotions), alongside those investigated in this study. Clearly, too, the closeness of the couple could best be measured preloss (which was not an option in this study). Likewise, although our selected types of bond seem central (at least in Western cultures), other forms and relationships with grief outcome are conceivable. For example, Field (2008) drew attention to research in Bali by Wikan, demonstrating that continuing bonds are linked to beliefs about health and sanity (in short: expressing a continued bond would be frowned on because it would affect health and sanity negatively). Continued efforts also need to be made to avoid conceptual overlap between grief and continuing bonds, and to include non-grief-specific symptom measures as we did, to avoid this possibility. Naturally, the correlation we found between relinquishment of bonds with grief could indicate that we have been unsuccessful in separating these variables conceptually. However, a significant correlation does not necessarily mean conceptual overlap but simply that the two variables are associated. In addition, the relationships we found with (un)expectedness of death pertained not only to grief but also to depression, where there is no conceptual overlap.

Our sample was limited to a fairly small number of younger widowed persons. We have no reason to assume that the relationships between expectedness of loss, continuing bonds, and adaptation would be different among older persons or those suffering other types of loss, but extension to other subgroups 
of bereaved persons is recommended (also, other cultures may exhibit different patterns of association between these variables). Likewise, although the patterns of results seem quite consistent, confirmation using larger samples and extending the range of behaviors included in "continuing bonds" would add to knowledge. Our two core dimensions, though following existing scientific literature, nevertheless represent only part of what "continuing bonds" incorporates; a multidimensional approach including phenomena such as internalization of the deceased would help establish validity. Similarly, room for improvement pertains to the measure of expectedness, which was assessed postloss (perceptions could be tainted for all participants by the fact that death happened) and which is notoriously difficult to assess (e.g., an "unexpected" death may in some sense be expected, as when a fatal accident follows persistent high-risk-taking behavior). Finally, analyses could be extended: We restricted analyses to using the assessment of continuing bonds at Time 1 because we were interested in the effect continuing bonds has on coping with a loss or coping outcome (grief, depression) and not in how coping with a loss modified continuing bonds. Therefore we took the measure that was nearest in time to bereavement. Clearly, the meaning and value of continuing bonds could change over time for a bereaved person. For example, it may be less detrimental to leave the possessions of the deceased placed as they had been in the early months after loss, than it would be to do so over subsequent years.

Despite the above-mentioned limitations, our study has identified subgroup differences in the value of continuing bonds with a deceased person. Most notably, it has shown that those who retain strong ties and who have experienced a sudden bereavement have the most difficulty in adjustment over time. It has shown the importance of extending research to include a new type of variable in the examination of continuing bonds in adjustment, one that not only fits well within the attachment theory framework but that has potential applied implications. Our study suggests the possibility that for some bereaved people, under certain circumstances, continuing bonds may not be helpful; it could even be harmful. Drawing implications from our results, it might be advisable for caregivers working with bereaved persons to focus on the nature of the continuing bond particularly among clients who have experienced a sudden relinquishment of their relationship through unexpected death. Close bonds may cause more difficulty for bereaved persons in this category than for those whose loss was expected.

\section{References}

Barry, L., Kasl, S., \& Prigerson, H. (2002). Psychiatric disorders among bereaved persons: The role of perceived circumstances of death and preparedness for death. American Journal of Geriatric Psychiatry, 10, 447-457.

Boelen, P., Stroebe, M., Schut, H., \& Zijerveld, A. (2006). Continuing bonds and grief: A retrospective analysis. Death Studies, 30, 767-776.

Bowlby, J. (1953). Child care and the growth of love. Harmondsworth, UK: Penguin Books.

Bowlby, J. (1980). Attachment and loss: Vol. 2. Loss: Sadness and depression. Harmondsworth, UK: Penguin.

Carr, D., House, J., Wortman, C., Nesse, R., \& Kessler, R. (2001) Psychological adjustment to sudden and anticipated spousal loss among older widowed persons. Journals of Gerontology, Series B, 56, S237-S248.

Caserta, M., Lund, D., Utz, R., \& de Vries, B. (2009). Stress-related growth among the recently bereaved. Aging and Mental Health, 13, 463-476.

Cassidy, J. \& Shaver, P. (2008). Handbook of attachment: Theory, practice and clinical applications (2nd ed.). New York: Guilford.

Faschingbauer, T. (1981). Texas revised inventory of grief manual. Houston, TX: Honeycomb.

Feeney, J. \& Hohaus, L. (2005). Attachment and spousal caregiving. Personal Relationships, 8, 21-39.

Field, N. (2008). Whether to relinquish or maintain a bond with the deceased. In M. Stroebe, R. O. Hansson, H. Schut, \& W. Stroebe (Eds.), Handbook of bereavement research and practice: Advances in theory and intervention (pp. 113-132). Washington, DC: American Psychological Association Press.

Field, N., \& Friedrichs, M. (2004). Continuing bonds in coping with the death of a husband. Death Studies, 28, 597-620.

Field, N. P., Gal-Oz, E., \& Bonanno, G. (2003). Continuing bonds and adjustment at 5 years after the death of a spouse. Journal of Consulting and Clinical Psychology, 71, 110-117.

Field, N., Gao, B., \& Paderna, L. (2005). Continuing bonds in bereavement: An attachment theory based perspective. Death Studies, 29, 1-23.

Field, N., Nichols, C., Holen, A., \& Horowitz, M. (1999). The relation of continuing attachment to adjustment 
in conjugal bereavement. Journal of Consulting and Clinical Psychology, 67, 212-218.

Fraley, C., \& Davis, K. (2005) Attachment formation and transfer in young adults' close friendships and romantic relationships. Personal Relationships, 4, $131-144$.

Freud, S. (1957). Mourning and melancholia. In J. Strachey (Ed. \& Trans.) Standard edition of the complete psychological works of Sigmund Freud (pp. 152-170). London: Hogarth. (Original work published 1917)

Hazan, C., \& Shaver, P. (1987). Romantic love conceptualized as an attachment process. Journal of Personality and Social Psychology, 52, 511-524.

Kammer, D. (1983). Eine Untersuchung der psychometrischen Eigenschaften des deutschen BeckDepressionsinventars (BDI) [Beck Depression Inventory]. Diagnostica, 28, 48-60.

Klass, D., Silverman, P., \& Nickman, S. (Eds.). (1996). Continuing bonds: New understandings of grief. Washington, DC: American Psychological Association Press.

Mikulincer, M., \& Shaver, P. (2010) Attachment theory and emotions in close relationships: Exploring the attachment-related dynamics of emotional reactions to relational events. Personal Relationships, 12, $149-168$.

Ong, A., Bergeman, C., \& Bisconti, T. (2005). Unique effects of daily perceived control on anxiety symptomatology during conjugal bereavement. Personality and Individual Differences, 38, 1057-1067.

Parkes, C. M. (2006). Love and loss: The roots of grief and its complications. London: Routledge.

Prigerson, H. (1995). Inventory of complicated grief: A scale to measure maladaptive symptoms of loss. Psychiatry Research, 59, 65-79.

Prigerson, H., Horowitz, M., Jacobs, S., Parkes, C., Aslan, M., Goodkin, K., ... Maciejewski, P. (2009). Prolonged grief disorder: Psychometric validation of criteria proposed for DSM-V and ICD-11. PLoS Medicine, 6, e1000121.

Rando, T. (1984). Grief, dying and death: Clinical interventions for caregivers. Champaign, IL: Research Press.

Raphael, B. (1983). The anatomy of bereavement. New York: Basic Books.
Sanders, C. (1989). Grief: The mourning after. New York: Wiley.

Scharfe, E., \& Bartholomew, K. (1994). Reliability and stability of adult attachment patterns. Personal Relationships, 1, 23-43.

Schut, H., Stroebe, M., Boelen, P., \& Zijerveld, A. (2006). Continuing relationships with the deceased: Disentangling bonds and grief. Death Studies, 30, 757-766.

Shuchter, S., \& Zisook, S. (1993). The course of normal grief. In M. Stroebe, W. Stroebe, \& R. O. Hansson (Eds.), Handbook of bereavement: Theory, research, and intervention (pp. 23-43). New York: Cambridge University Press.

Stroebe, M., Gergen, M., Gergen, K., \& Stroebe, W. (1992). Broken hearts: Love and death in historical perspective. American Psychologist, 47, 1205-1212.

Stroebe, M., \& Schut, H. (2005). To continue or relinquish bonds? A review of consequences for the bereaved. Death Studies, 29, 477-494.

Stroebe, M., Schut, H., \& Boerner, K. (2010). Continuing bonds in adaptation to bereavement: Toward theoretical integration. Clinical Psychology Review, 30, 259-268.

Stroebe, M., \& Stroebe, W. (1989). Who participates in bereavement research? An empirical study of the impact of health on attrition. Omega: Journal of Death and Dying, 20, 1-29.

Stroebe, W., \& Stroebe, M. (1993). Determinants of adjustment to bereavement in younger widows and widowers. In M. Stroebe, W. Stroebe, \& R. O. Hansson (Eds.), Handbook of bereavement (pp. 208-226). New York: Cambridge University Press.

Wijngaards-de Meij, L., Stroebe, M., Schut, H., Stroebe, W, van den Bout, J., Heijmans, P., \& Dijkstra, I. (2005). Couples at risk following the death of their child: Predictors of grief versus depression. Journal of Consulting and Clinical Psychology, 73, 617-623.

Worden, W. (2008). Grief counselling and grief therapy: A handbook for the mental health practitioner (4th ed.). New York: Springer. (Original work published 1982) 